\title{
Ankylosing pelvitrochanteric heterotopic ossification in a patient with spinal cord injury
}

\author{
Serkan Gurcan, ${ }^{1}$ Selahattin Ozyurek, ${ }^{2}$ Ozkan Kose, ${ }^{3}$ Ali Sehirlioglu ${ }^{4}$
}

'Department of Orthopaedics and Traumatology, Cag Hospital, Ankara, Turkey ${ }^{2}$ Department of Orthopedic Surgery, Aksaz Military Hospital, Mugla, Turkey ${ }^{3}$ Department of Orthopaedics and Traumatology, Antalya Education and Research Hospital, Antalya, Turkey ${ }^{4}$ Department of Orthopaedics and Traumatology, Akay Hospital, Ankara, Turkey

\section{Correspondence to} Selahattin Ozyurek, fsozyurek@yahoo.com

\section{SUMMARY}

Heterotopic ossification is a frequent complication after spinal cord injury. It usually develops around major weight bearing joints. However, ankylosing hip is a rare presentation. Various treatment methods have been reported and advocated as efficacious methods for management of heterotopic ossification. We report a case of ankylosing pelvitrochanteric heterotopic ossification treated with surgical excision before full maturation, postoperative radiation therapy and indomethacine without recurrence after 1 year. Treatment options are discussed in this particular case.

\section{BACKGROUND}

Heterotopic ossification (HO) is defined as the presence of lamellar bone at locations where bone normally does not exist. This syndrome is most commonly seen following neurological disorders such as traumatic brain or spinal cord injury, or following joint surgery or severe burns. Patients with neurogenic HO develop lesions around larger joints. The hip is the most common location, followed by the knees and elbows but complete ankylosis is a rare presentation. ${ }^{12}$

Radiation therapy, surgical resection, biphosphonates and various non-steroidal anti-inflammatory drugs (NSAIDs) have been reported and advocated as efficacious methods for management of HO. We report a case of ankylosing pelvitrochanteric $\mathrm{HO}$ in a patient with spinal cord injury treated successfully with surgical excision, postoperative radiation therapy and indomethacin.

\section{CASE PRESENTATION}

A 29-year-old paraplegic patient referred to our clinic with a significant restriction of right hip movement. The patient suffered T8-T9 fracture dislocation and brain contusion 1 year ago in a traffic accident. The patient stayed in intensive care unit under barbiturate sedation for 2 months owing to brain oedema. The patient recovered slowly and was transferred to the spinal rehabilitation unit 3 months after the initial injury. During the next 6 months the patient developed total ankylosis of the right hip that prevents sitting position in the wheelchair and perineal hygiene.

On physical examination, right hip was held in the extended position because of large hard mass extending from iliac crest down to the upper third of the thigh, causing fixation of the hip joint in the extended position. It was impossible to flex or abduct the hip joint to maintain a normal sitting posture and perform perineal cleaning.

\section{INVESTIGATIONS}

Radiographical examination revealed diffuse $\mathrm{HO}$ and ankylosis of the hip (figure 1A). A CT

\footnotetext{
To cite: Gurcan $S$, Ozyurek S, Kose O, et al. BMJ Case Rep Published online: [please include Day Month Year] doi:10.1136/ bcr-2013-009983
}

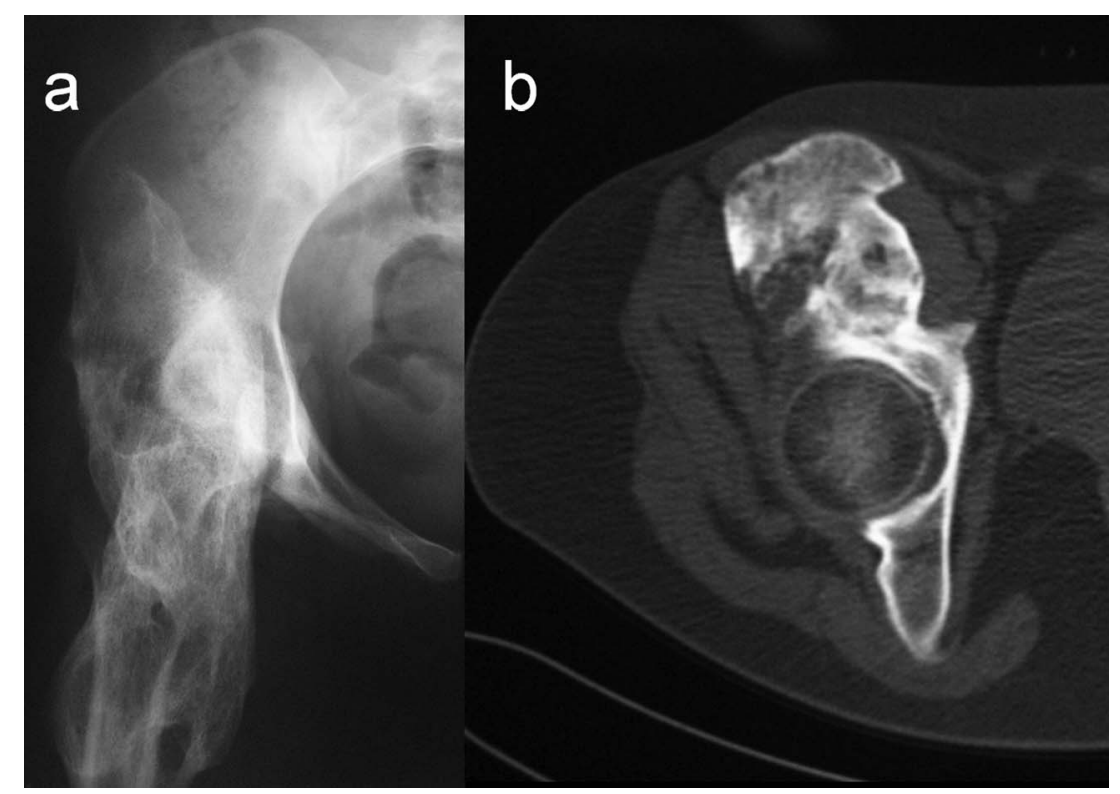

Figure 1 (A) Anteroposterior hip x-ray at initial admission; complete anklyosis of the hip from pelvis to trochanteric region is seen. (B) CT of the hip revealed normal joint space with a bridging heterotopic ossification over the anterior joint capsule. 
Figure 2 (A) Intraoperative appearance of the heterotopic bone mass through the anterior approach. (B) Resected bone. (C) Early postoperative hip radiograph of the patient.

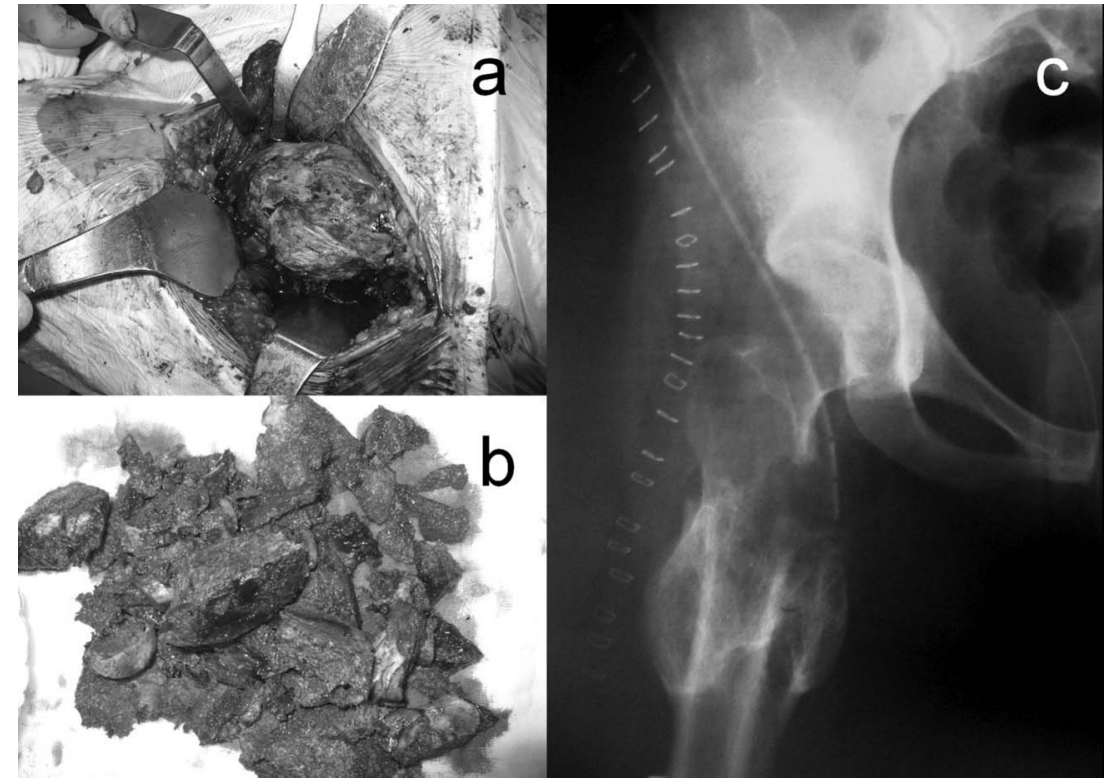

examination showed pelvitrochanteric HO sparing the hip joint itself (figure 1B). Bone scintigraphy showed very high incorporation around the right hip.

\section{TREATMENT}

Surgical resection of $\mathrm{HO}$ was carried out using anterior approach. There was a clear demarcation zone between the posterior periosteum of the mass and the anterior hip joint capsule

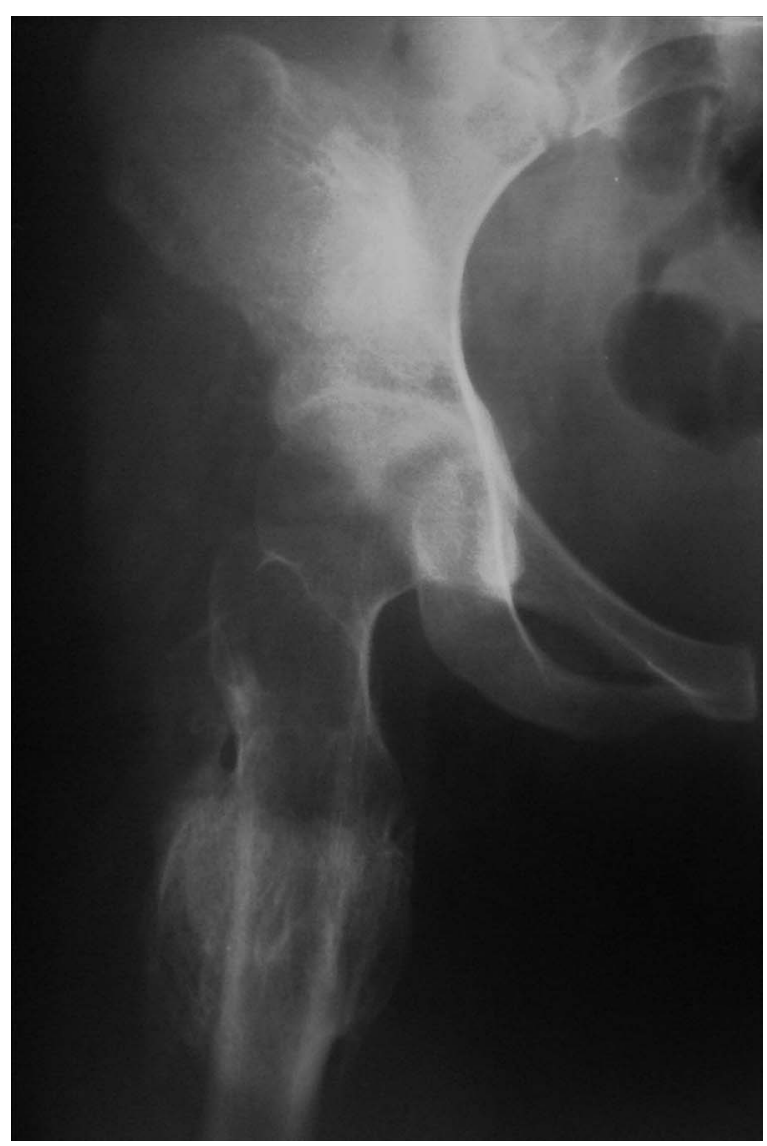

Figure 3 Final hip radiograph of the patient. (figure 2A,B). The HO surrounding the upper third of the femur was not disturbed. On completion of the excision of the cephalad mass it was possible to flex and abduct the hip joints to $100^{\circ}$ and $30^{\circ}$, respectively, on the operating table. The total blood loss was approximately $1200 \mathrm{ml}$. Postoperative hip radiograph showed clearance of the ankylosis (figure 2C). Her postoperative course was uneventful without wound complications. Passive movement of the hip joint was carried out throughout the healing period. 3 weeks following surgery the patient was transferred into a wheelchair where the patient was able to bend forward.

Prophylaxis for recurrence of $\mathrm{HO}$ included postoperative single-dose radiation ( $8 \mathrm{~Gy}$ ) and postoperative treatment with indomethacin at a dose of $150 \mathrm{mg} /$ day.

\section{OUTCOME AND FOLLOW-UP}

At the final follow-up 12 months after surgery, the range of hip movements was still preserved with no sign of recurrence observed on direct radiographs (figure 3 ).

\section{DISCUSSION}

Heterotopic bone formation begins within 2 months after neurological injury and is usually fully developed by 2 years. Sometimes, the heterotopic bone may be massive and cause complete ankylosis of the affected joint. A limitation of the range of joint motion may have serious consequences for daily functioning of people who are already severely incapacitated because of their original lesion. Increased contractures and spasticity, pressure ulcers and increasing pain further compromise the patient's capabilities. ${ }^{3}$

Surgery is the only treatment that is capable of removing an already formed bone, but complications frequently occur such as deep venous thrombosis, infections, pressure ulcers and major blood loss. Moreover, surgical resection alone is associated with an extremely high recurrence rate. Consequently, surgical resection must always be combined with NSAID or postoperative radiation therapy. Indications for surgery include improvement of the range of motion, for example, to enable patients to sit properly, reduction of contractures, prevention of pressure ulcers and intractable pain. The optimal timing of surgery is still controversial. Usually, it is suggested to wait until complete maturation of the ectopic bone, mainly to avoid 
recurrences. Maturation is manifested by normalisation of the scintigraphic findings and usually takes $12-18$ months. There is a growing tendency to pay more attention to the patients' neurological condition and to delay resection until he or she is maximally recovered from brain or spinal cord injury. ${ }^{4}$ Three-phase bone scintigraphy is used for both diagnostic and therapeutic follow-up purposes, and is the most sensitive imaging modality for early detection of HO. The first two phases are indicative of hyperaemia and blood pooling, which are the precursors of an ossification process. Bone scintigraphy is usually positive after $2-4$ weeks. It can also be used to assess the maturity of HO. Serial bone scans are used to monitor the metabolic activity of $\mathrm{HO}$ so as to determine the optimal timing for surgical resection, and to predict postoperative occurrence. Before surgery, MRI and CT are valuable to assess the relation with blood vessels and peripheral nerve structures. ${ }^{5}$

Although early surgical excision before maturation has a high risk of recurrence, in case of complete ankylosis it may be compulsory for the patient's daily life quality. Postoperative low-dose radiotherapy and indomethacin combination is effective to prevent recurrences.
Contributors All authors have contributed equally in preparing the manuscript research, review, writing and all of them have approved the final draft of the article.

Competing interests None.

Patient consent Obtained.

Provenance and peer review Not commissioned; externally peer reviewed.

\section{REFERENCES}

1 McCarthy EF, Sundaram M. Heterotopic ossification: a review. Skeletal Radiol 2005;34:609-19.

2 Garland DE, Blum CE, Waters RL. Periarticular heterotopic ossification in head-injured adults. Incidence and location. J Bone Joint Surg Am 1980;62:1143-6.

3 Vanden Bossche L, Vanderstraeten G. Heterotopic ossification: a review. J Rehabil Med 2005;37:129-36.

4 Moore TJ. Functional outcome following surgical excision of heterotopic ossification in patients with traumatic brain injury. J Orthop Trauma 1993;7:11-14.

5 Jensen LL, Halar E, Little JW, et al. Neurogenic heterotopic ossification. Am J Phys Med 1987;66:351-63.

\section{Learning points}

- Heterotopic ossification (HO) is defined as the presence of lamellar bone at locations where bone normally does not exist.

- This syndrome is most commonly seen following neurological disorders such as traumatic brain or spinal cord injury, or following joint surgery or severe burns.

- Patients with neurogenic HO develop lesions around larger joints. The hip is the most common location, followed by the knees and elbows but complete ankylosis is a rare presentation.

Copyright 2013 BMJ Publishing Group. All rights reserved. For permission to reuse any of this content visit http://group.bmj.com/group/rights-licensing/permissions.

BMJ Case Report Fellows may re-use this article for personal use and teaching without any further permission.

Become a Fellow of BMJ Case Reports today and you can:

- Submit as many cases as you like

- Enjoy fast sympathetic peer review and rapid publication of accepted articles

- Access all the published articles

- Re-use any of the published material for personal use and teaching without further permission

For information on Institutional Fellowships contact consortiasales@bmjgroup.com

Visit casereports.bmj.com for more articles like this and to become a Fellow 